in vivo $32: 1533-1540(2018)$

doi:10.21873/invivo.11411

\title{
CD44 Predicts Early Recurrence in Pancreatic Cancer Patients Undergoing Radical Surgery
}

\author{
CHIH-PO HSU ${ }^{1 *}$, LI-YU LEE ${ }^{2 *}$, JUN-TE HSU ${ }^{1}$, YU-PAO HSU ${ }^{1}$, YU-TUNG WU ${ }^{1}$, \\ SHANG-YU WANG ${ }^{1}$, CHUN-NAN YEH ${ }^{1}$, TSE-CHING CHEN ${ }^{2}$ and TSANN-LONG HWANG ${ }^{1}$ \\ ${ }^{1}$ Department of General Surgery, Chang Gung Memorial Hospital at Linkou, \\ Chang Gung University College of Medicine, Taoyuan, Taiwan, R.O.C.; \\ ${ }^{2}$ Department of Pathology, Chang Gung Memorial Hospital at Linkou, \\ Chang Gung University College of Medicine, Taoyuan, Taiwan, R.O.C.
}

\begin{abstract}
Background/Aim: Pancreatic ductal adenocarcinoma (PDAC) is one of the most aggressive types of digestive cancer. Recurrence within one year after surgery is inevitable in most PDAC patients. Recently, cluster of differentiation 44 (CD44) has been shown to be associated with tumor initiation, metastasis and prognosis. This study aimed to explore the correlation of CD44 expression with clinicopathological factors and the role of CD44 in predicting early recurrence (ER) in PDAC patients after radical surgery. Materials and Methods: PDAC patients who underwent radical resection between January 1999 and March 2015 were enrolled in this study. Tumor recurrence within 6 months after surgery was defined as ER. Immunohistochemical staining was performed with antiCD44 antibodies. The association between clinicopathological parameters and CD44 expression was analyzed. Predictors for ER were also assessed with univariate and multivariate analyses. Results: Overall, 155 patients were included in this study. Univariate analysis revealed CA19-9 levels ( $p=0.014), C D 44$ histoscores (H-scores; $p=0.002)$, differentiation $(p=0.010)$, nodal status $(p=0.005)$, stage $(p=0.003)$, vascular invasion $(p=0.007)$, lymphatic invasion $(p<0.001)$ and perineural invasion $(p=0.042)$ as risk factors for ER. In multivariate analysis, high CA19-9 levels and CD44 H-scores and poor differentiation independently
\end{abstract}

This article is freely accessible online.

*These Authors contributed equally to this study.

Correspondence to: Drs. Jun-Te Hsu or Tsann-Long Hwang, Department of Surgery, Chang Gung Memorial Hospital at Linkou, No. 5, Fu-Hsing Street, Kwei-Shan District, Taoyuan City, 333, Taiwan, R.O.C. Tel: +886 33281200 Ext. 3219, Fax: +886 33285818, e-mail: hsujt2813@adm.cgmh.org.tw or hwangtl@cgmh.org.tw

Key Words: CD44, early recurrence, pancreatic cancer, surgery. predicted ER. Conclusion: High CA19-9 levels, CD44 Hscores and poor differentiation are independent predictors for ER in PDAC patients undergoing radical resection. Therefore, the determination of CD44 expression might help in identifying patients at a high risk of ER for more aggressive treatment after radical surgery.

Pancreatic ductal adenocarcinoma (PDAC) is the fourth most common cause of cancer-related death worldwide, with an $8 \%$ 5-year survival rate for all stages of disease (1). Although various treatment modalities are available, only radical tumor resection can potentially provide a curative option for PDAC patients $(2,3)$. Nonetheless, due to the aggressive nature of the disease, recurrence within 1 year after surgery might be inevitable for many patients. Our previous study showed the 3-year and 5-year overall survival rates were $21.4 \%$ and $10.1 \%$, respectively (4).

Cancer stem cells (CSCs), a subpopulation of tumor cells, are responsible for tumor initiation, growth, metastasis, and resistance to chemotherapy (5). Pancreatic CSCs have been identified by flow cytometry using cell markers, including cluster of differentiation 44 (CD44), CD24, epithelial-specific antigens, CD133, aldehyde dehydrogenase 1 , and c-Met $(5,6)$. Among these markers, CD44 is a transmembrane glycoprotein receptor that binds hyaluronic acid (HA). The CD44-HA complex effectively plays an important role in cellular survival, differentiation, adhesion, and migration (7-9). Applying CD44 as a biomarker could effectively help in identifying CSCs in human cancers including breast, stomach, head and neck, pancreatic and other cancer $(9,10)$. Inhibition of CD44 expression can slow pancreatic cancer growth, invasion and recurrence rate $(11,12)$. To the best of our knowledge, no study has reported an association between CD44 expression and early recurrence (ER) in PDAC patients undergoing radical surgery. The aim of the present study was to analyze CD44 expression and clinicopathological factors for predicting ER in PDAC patients after radical resection. 


\section{Materials and Methods}

The records of PDAC patients undergoing surgical resection between January 1999 and March 2015 at the Chang Gung Memorial Hospital, Linkou, Taiwan were retrospectively reviewed. After the exclusion of 8 PDAC patients with hospital mortality, 62 patients with positive resection margins, and 11 patients with follow-up period shorter than 6 months, a total of 155 patients were recruited in this study. Tumor relapse within 6 months after surgery was defined as ER. The follow-up duration was measured from the time of surgery until death or the last follow-up time (December 2016). Clinicopathological data including sex, age, serum albumin levels, tumor markers such as carcinoembryonic antigen (CEA) and carbohydrate antigen (CA) 19-9, type of operation, tumor size, tumor location, differentiation, stage, vascular invasion, lymphatic invasion, perineural invasion, surgical complications, and the administration of chemotherapy or radiotherapy were reviewed. The tumor was staged according to the 8th edition of the American Joint Committee on Cancer (AJCC). This study was approved by the institutional review board of the Chang Gung Memorial Hospital (No. 104-2308B).

Immunohistochemistry. Immunohistochemistry for CD44 was performed on formalin-fixed paraffin-embedded tissues. A single representative block from each tumor was sectioned at $3-\mu \mathrm{m}$ thickness and placed onto positively charged slides. The slides were then stained using a Bond-Max Autostainer (Leica Biosystems, Heidelberger, Germany). Briefly, the slides were dewaxed in Bond Dewax solution (Leica Biosystems) and hydrated in Bond Wash solution (Leica Biosystems). Antigen retrieval was performed at an alkaline $\mathrm{pH}$ of 9 using Epitope Retrieval 2 solution (Leica Biosystems) for $20 \mathrm{~min}$ at $100^{\circ} \mathrm{C}$. The slides were then incubated with the primary antibody at a concentration of 1:100 for $30 \mathrm{~min}$ at room temperature. The Bond Polymer Refine Detection (DS9800) kit was used for detection, with incubation with post primary for $8 \mathrm{~min}$, polymer for $8 \mathrm{~min}$, $\mathrm{DAB}$ for $5 \mathrm{~min}$ and hematoxylin for $5 \mathrm{~min}$.

Assessment of immunohistochemical staining. The staining results were independently scored by two of the authors (L.Y.L. and T.C.C.) who were blinded to all of the clinicopathological variables (Figure 1). To assess the expression of CD44 immunostaining, a semiquantitative histoscore (H-score) was used. The intensity of cytoplasmic and membranous immunostaining was scored on a scale of 0 (no staining) to 3 (strongest intensity), and the percentage of stained cells was estimated at each intensity. The percentage of cells (from 0 to 100) was multiplied by the corresponding immunostaining intensity (from 0 to 3 ) to obtain an $\mathrm{H}$-score in the range of 0 to 300 .

Treatment protocols. For tumors in the head or uncinate process of the pancreas, the standard treatment is classic or pylorus-preserving pancreaticoduodenectomy. Subtotal or distal pancreatectomy with splenectomy is performed if the tumor is located at the body or tail of the pancreas. In our study, medically fit patients usually received chemotherapy with fluoropyrimidine-based, gemcitabine or gemcitabine plus cisplatin or S-1 regimens 6-8 weeks after surgery. Selected patients underwent intraoperative radiotherapy or postoperative external beam radiation therapy coupled with gemcitabine or 5-fluorouracil.
Postoperative follow-up evaluation. The regular postoperative follow-up evaluation included physical examination, blood chemistry tests and tumor marker analysis (CEA and CA19-9). Imaging studies including abdominal ultrasonography and computerized tomography/magnetic resonance imaging were performed every 3-6 months during the first 2 years after surgery and every 6-12 months thereafter. Tumor recurrence was defined by clinical judgement based on laboratory tests, imaging findings, tissue analysis or patients' outcomes. The median follow-up time in this study was 16.1 months.

Statistical analysis. Baseline characteristics of the two outcome groups were compared using Pearson's chi-square or Fisher's exact tests. Any significant variable $(p<0.05)$ on univariate analysis was included in multivariate models for logistic regression analysis. Survival curves were depicted by the KaplanMeier method and compared using the log-rank test. The optimal cutoff value of CD44 $\mathrm{H}$-score was defined by analyzing the receiver operating characteristic curve in terms of ER after surgery. A value of $p<0.05$ was considered significant. All statistical analyses were performed using SPSS for Windows version 20.0 (SPSS Inc., Chicago, IL, USA).

\section{Results}

The clinicopathological data are summarized in Table I. There were $88(56.8 \%)$ male and $67(43.2 \%)$ female patients. The median age of patients was 63.1 years. The median values of CEA, CA19-9 and CD44 H-score were 3.0, 158.6 and 22.0, respectively. Ninety-six $(61.9 \%)$ patients underwent classic Whipple procedure, and $38(24.5 \%)$ pylorus-preserving pancreaticoduodenectomy. The median tumor size was $3.3 \mathrm{~cm}$. Stage I, II and III diseases were noted in 51, 86 and 18 patients, respectively. Sixty-six $(42.6 \%)$ patients experienced surgical complications. Postoperative chemotherapy and radiotherapy were administered to $102(65.8 \%)$ and $11(7.1 \%)$ patients, respectively.

Table II shows the results of univariate analysis of various clinicopathological factors associated with ER in PDAC patients undergoing radical resection. CA19-9 levels, CD44 $\mathrm{H}$-scores, differentiation, nodal status, stage, and presence of vascular, lymphatic, and perineural invasion significantly affected ER. No significant differences in recurrence time were observed irrespective of sex, age, albumin levels, CEA values, type of operation, tumor location, $\mathrm{T}$ status, surgical complications, or the administration of postoperative chemotherapy or radiation. In multivariate analysis, the independent predictors for ER were CA19-9 levels, CD44 Hscores and differentiation (Table III).

\section{Discussion}

PDAC is known for its aggressive tumor behavior such as local invasion, early metastasis, and poor prognosis. Recurrence within 1 year after surgery is inevitable and frequent for most patients. The present study is the first to 

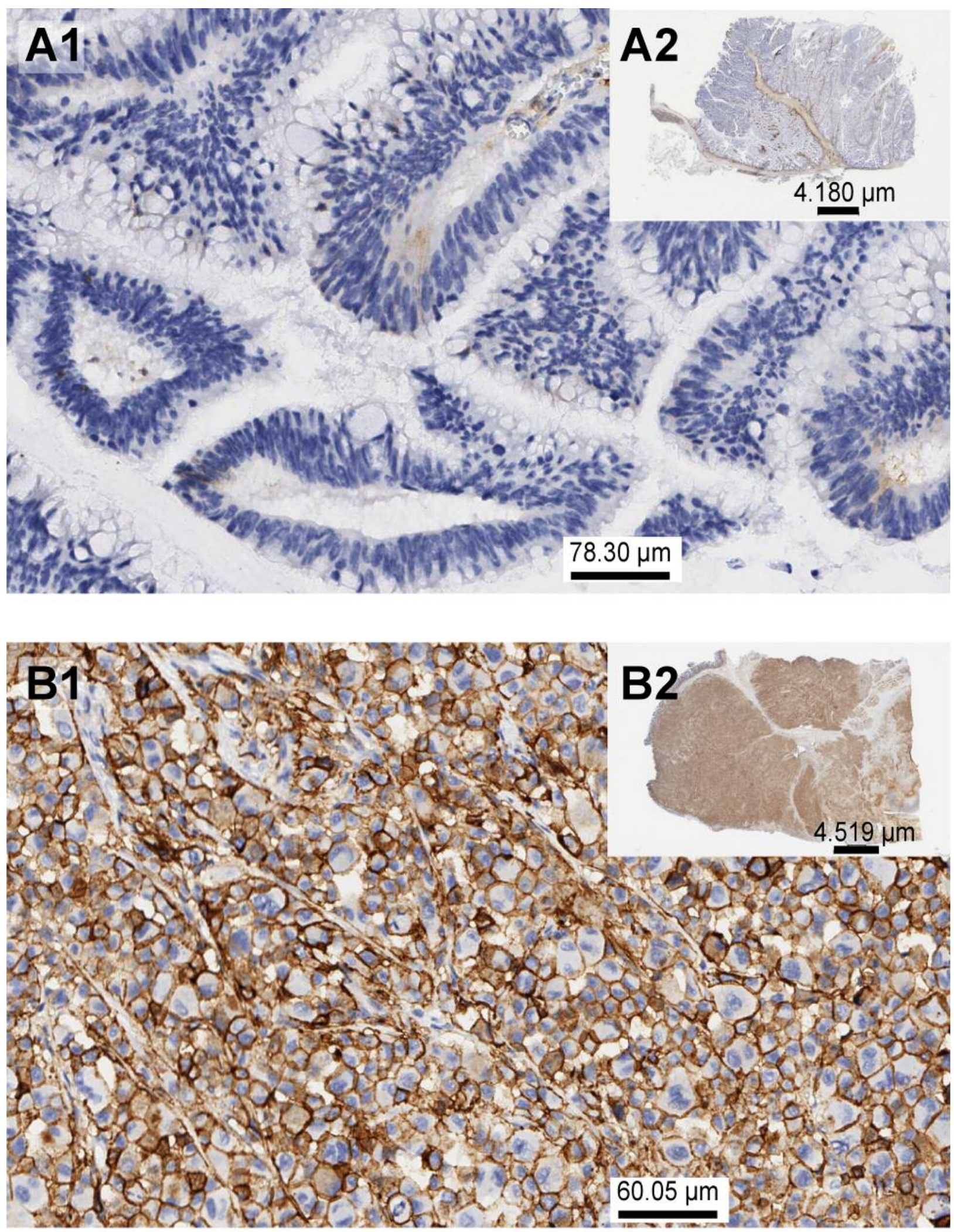

Figure 1. Representative immunohistochemistry image for CD44 staining in PDAC tissue. A-1: high power view of negative staining (H-score=0). A-2: scan view of negative staining. B-1: high power view of positive staining (H-score $=270)$. B-2: scan view of positive staining. 
Table I. Demographic characteristics of patients undergoing radical surgery.

\begin{tabular}{|c|c|c|}
\hline Parameters & $\begin{array}{l}\text { Patient number } \\
\text { or median value }\end{array}$ & $\%$ \\
\hline \multicolumn{3}{|l|}{ Gender } \\
\hline Male & 88 & 56.8 \\
\hline Female & 67 & 43.2 \\
\hline Age (years), median (IQR) & $62(18)$ & \\
\hline Albumin (g/dl), median (IQR) & $3.9(0.8)$ & \\
\hline CEA (ng/ml), median (IQR) & $3.0(3.8)$ & \\
\hline CA19-9 (U/ml), median (IQR) & $158.6(495.0)$ & \\
\hline CD44 H-score, median (IQR) & $20.0(55.0)$ & \\
\hline \multicolumn{3}{|l|}{ Type of operation } \\
\hline Whipple & 96 & 62.0 \\
\hline PPPD & 38 & 24.5 \\
\hline Other & 21 & 13.5 \\
\hline Tumor size $(\mathrm{cm})$, median (IQR) & $3.0(1.5)$ & \\
\hline \multicolumn{3}{|l|}{ Tumor location } \\
\hline Head & 118 & 76.1 \\
\hline Uncinate process & 18 & 11.6 \\
\hline Body/tail & 19 & 12.3 \\
\hline \multicolumn{3}{|l|}{ Differentiation } \\
\hline No & 127 & 81.9 \\
\hline Yes & 28 & 18.1 \\
\hline \multicolumn{3}{|l|}{ T status } \\
\hline $\mathrm{T} 1$ & 5 & 3.2 \\
\hline $\mathrm{T} 2$ & 21 & 13.5 \\
\hline $\mathrm{T} 3$ & 129 & 83.3 \\
\hline \multicolumn{3}{|l|}{$\mathrm{N}$ status } \\
\hline Negative & 58 & 37.4 \\
\hline Positive & 97 & 62.6 \\
\hline \multicolumn{3}{|l|}{ Stage } \\
\hline I & 51 & 32.9 \\
\hline II & 86 & 55.5 \\
\hline III & 18 & 11.6 \\
\hline \multicolumn{3}{|l|}{ Vascular invasion* } \\
\hline No & 114 & 75.0 \\
\hline Yes & 38 & 25.0 \\
\hline \multicolumn{3}{|l|}{ Lymphatic invasion* } \\
\hline No & 80 & 52.6 \\
\hline Yes & 72 & 47.4 \\
\hline \multicolumn{3}{|l|}{ Perineural invasion* } \\
\hline No & 36 & 23.7 \\
\hline Yes & 116 & 76.3 \\
\hline \multicolumn{3}{|l|}{ Surgical complications } \\
\hline No & 89 & 57.4 \\
\hline Yes & 66 & 42.6 \\
\hline \multicolumn{3}{|l|}{ Chemotherapy } \\
\hline No & 53 & 34.2 \\
\hline Yes & 102 & 65.8 \\
\hline \multicolumn{3}{|l|}{ Radiotherapy } \\
\hline No & 144 & 92.9 \\
\hline Yes & 11 & 7.1 \\
\hline
\end{tabular}

IQR: Interquartile range; CA19-9: carbohydrate antigen 19-9; CEA: carcinoembryonic antigen; CD44: cluster of differentiation 44; H-score: histoscore; PPPD: pylorus-preserving pancreaticoduodenectomy. *Not all data were available.
Table II. Clinicopathological features of patients in terms of recurrence time.

\begin{tabular}{|c|c|c|c|}
\hline Parameters & $\begin{array}{c}\text { Recurrence } \\
\leq 6 \text { months }(\mathrm{n}=61)\end{array}$ & $\begin{array}{c}\text { Recurrence } \\
>6 \text { months }(\mathrm{n}=94)\end{array}$ & $p$-Value \\
\hline Gender & & & 0.075 \\
\hline Male & $40(65.6)$ & $48(51.1)$ & \\
\hline Female & $21(34.4)$ & $46(48.9)$ & \\
\hline Age (years) & & & 0.465 \\
\hline$\leq 65$ & $38(62.3)$ & $53(56.4)$ & \\
\hline$>65$ & $23(37.7)$ & $41(43.6)$ & \\
\hline Albumin (g/dl) & & & 0.352 \\
\hline$\leq 3.5$ & $11(19.6)$ & $23(26.4)$ & \\
\hline$>3.5$ & $45(80.4)$ & $64(73.6)$ & \\
\hline CEA (ng/ml) & & & 0.770 \\
\hline$\leq 5$ & $41(74.5)$ & $60(72.3)$ & \\
\hline$>5$ & $14(25.5)$ & $23(27.7)$ & \\
\hline CA19-9 (U/ml) & & & 0.014 \\
\hline$\leq 37$ & $9(15.0)$ & $30(33.0)$ & \\
\hline$>37$ & $51(85.0)$ & $61(67.0)$ & \\
\hline CD44 H-score & & & 0.002 \\
\hline$\leq 32$ & $27(44.3)$ & $65(69.1)$ & \\
\hline$>32$ & $34(55.7)$ & $29(30.9)$ & \\
\hline Type of operation & & & 0.227 \\
\hline Whipple & $36(59.1)$ & $60(63.8)$ & \\
\hline PPPD & $19(31.1)$ & $19(20.2)$ & \\
\hline Others & $6(9.8)$ & $15(16.0)$ & \\
\hline Tumor location & & & 0.188 \\
\hline Head & $46(75.4)$ & $72(76.6)$ & \\
\hline Uncinate process & $10(16.4)$ & $8(8.5)$ & \\
\hline Body/tail & $5(8.2)$ & $14(14.9)$ & \\
\hline Differentiation & & & 0.010 \\
\hline No & $56(91.8)$ & $71(75.5)$ & \\
\hline Yes & $5(8.2)$ & $23(24.5)$ & \\
\hline T status & & & 0.058 \\
\hline $\mathrm{T} 1$ & $8(13.1)$ & $18(19.1)$ & \\
\hline $\mathrm{T} 2$ & $37(60.7)$ & $65(69.2)$ & \\
\hline $\mathrm{T} 3$ & $16(26.2)$ & $11(11.7)$ & \\
\hline $\mathrm{N}$ status & & & 0.005 \\
\hline N0 & $14(23.0)$ & $44(46.9)$ & \\
\hline N1 & $36(59.0)$ & $43(45.7)$ & \\
\hline $\mathrm{N} 2$ & $11(18.0)$ & $7(7.4)$ & \\
\hline Stage & & & 0.003 \\
\hline I & $11(18.0)$ & $40(42.6)$ & \\
\hline II & $39(64.0)$ & $47(50.0)$ & \\
\hline III & $11(18.0)$ & $7(7.4)$ & \\
\hline Vascular invasion* & & & 0.007 \\
\hline No & $38(63.3)$ & $76(82.6)$ & \\
\hline Yes & $22(36.7)$ & $16(17.4)$ & \\
\hline Lymphatic invasion* & & & $<0.001$ \\
\hline No & $21(35.0)$ & $59(64.1)$ & \\
\hline Yes & $39(65.0)$ & $33(35.9)$ & \\
\hline Perineural invasion* & & & 0.042 \\
\hline No & $9(15.0)$ & $27(29.3)$ & \\
\hline Yes & $51(85.0)$ & $65(70.7)$ & \\
\hline Surgical complications & & & 0.095 \\
\hline No & $30(49.2)$ & $59(62.8)$ & \\
\hline Yes & $31(50.8)$ & $35(37.2)$ & \\
\hline Chemotherapy & & & 0.322 \\
\hline No & $18(29.5)$ & $35(37.2)$ & \\
\hline Yes & $43(70.5)$ & $59(62.8)$ & \\
\hline Radiotherapy & & & $>0.999$ \\
\hline No & $57(93.4)$ & $87(92.6)$ & \\
\hline Yes & $4(6.6)$ & $7(7.4)$ & \\
\hline
\end{tabular}

CA19-9: Carbohydrate antigen 19-9; CEA: carcinoembryonic antigen; CD44: cluster of differentiation 44; $\mathrm{H}$-score: histoscore. Values in parentheses are percentages. *Not all data were available. 
Table III. Multivariate analysis of predictive factors for early recurrence in patients undergoing radical surgery.

\begin{tabular}{|c|c|c|c|c|c|}
\hline \multirow[t]{3}{*}{ Parameters } & & \multicolumn{4}{|c|}{ Recurrence $\leq 6$ months } \\
\hline & & \multirow[t]{2}{*}{ Odds ratio } & \multicolumn{2}{|c|}{$95 \% \mathrm{CI}$ for odds ratio } & \multirow[t]{2}{*}{$p$-Value } \\
\hline & & & Lower & Upper & \\
\hline CA19-9 (U/ml) & $>37 / \leq 37$ & 2.788 & 1.084 & 7.169 & 0.033 \\
\hline CD44 H-score & $>32 / \leq 32$ & 2.483 & 1.157 & 5.327 & 0.020 \\
\hline Differentiation & No/yes & 4.091 & 1.258 & 13.300 & 0.019 \\
\hline \multirow[t]{2}{*}{ Stage } & $\mathrm{II} / \mathrm{I}$ & 2.162 & 0.860 & 5.436 & 0.101 \\
\hline & III/I & 3.748 & 0.947 & 14.829 & 0.060 \\
\hline Vascular invasion & Yes/no & 1.610 & 0.656 & 3.953 & 0.299 \\
\hline Lymphatic invasion & Yes/no & 2.072 & 0.873 & 4.914 & 0.098 \\
\hline Perineural invasion & Yes/no & 0.925 & 0.335 & 2.554 & 0.880 \\
\hline
\end{tabular}

CA19-9: Carbohydrate antigen 19-9; CD44: cluster of differentiation 44; H-score: histoscore; CI: confidence interval.

analyze the value of a CSC marker (CD44) and clinicopathological factors in predicting ER in PDAC patients undergoing radical surgery. Based on our results, CA19-9 levels, CD44 H-scores and differentiation were independent risk factors for ER.

Currently, the tumor-node-metastasis (TNM) staging system is not precise enough to predict patient prognosis. Recurrence time differs even in patients with the same TNM stage. Therefore, more molecular information relevant to the tumor is urgently needed to better identify patients who are at a high risk of ER, and these patients might need aggressive tailored therapies for better prognosis. CD44, a cell surface adhesion receptor encoded by a gene on the short arm of chromosome 11, is highly expressed in many cancers. Several systematic reviews and meta-analyses have reported the association between CD44 and tumor characteristics or prognosis in various cancers including head and neck, non-small cell lung, stomach, liver, kidney and ovarian cancer (13-18). For example, Chen et al. suggested that CD44 is related to advanced $\mathrm{T}$ and $\mathrm{N}$ status, high tumor grade and poor outcomes in pharyngeal and laryngeal cancer (13). Pre-clinical studies on the mechanism have also identified that CD44 overexpression is associated with angiogenesis, (19) which is a process of formation of new blood vessels (20). In contrast, studies have indicated that the inhibition of CD44 expression resulted in impaired endothelial function (20) and reduced the ability of endothelial cells to form vessel-like networks (21). In a clinical study, Choi et al. reported that the increased expression of CSC markers, especially keratin 19 (K19) and CD44, during the perioperative period can predict ER after radical surgery of hepatocellular carcinoma (22). Therefore, anti-CD44 therapy might become a new potential cancer treatment. Similar to our previous findings (23), studies have shown that CD44 is a poor prognostic factor in pancreatic cancer $(24,25)$. Early in 1998, Gotoda et al. reported that the expression of CD44v6 and CD44v2 was a useful predictor of poor outcomes in patients with curatively resected pancreatic cancer (24). A few years ago, Li et al. used an antibody against CD44s (standard isoform) to inhibit pancreatic tumor initiation and post-irradiation recurrence in a mouse model (25). Although in the animal study CD44 was shown to be correlated with unfavorable prognosis in PDAC, the relationship between CD44 and ER in human PDAC had not been reported. In our present work, it was observed for the first time that increased CD44 Hscores were associated with ER in PDAC. Nonetheless, further large-scale studies are required to confirm our results, and more pre-clinical studies are needed to clarify the precise mechanism of CD44 expression in PDAC patients experiencing ER.

CA19-9 has been widely studied as a serum marker of PDAC regarding many aspects including screening, diagnosis, resectability and prognostic determination, and postoperative surveillance. Other biomarkers have also emerged from preclinical and early clinical trials with an attempt to increase the sensitivity of early detection of PDAC (26-30). However, none of these biomarkers has replaced serum CA19-9 in clinical utility to date. The serum level of CA19-9, either preoperative or postoperative, is associated with long-term survival (31-36). In addition, studies have suggested that the preoperative CA19-9 level can help in predicting occult metastasis and the likelihood of a complete (R0) resection (31, 37-41). Studies have also indicated that preoperative serum levels of CA19-9 can predict patient outcomes $(41,42)$. Based on this perspective, high levels of preoperative CA19-9 might be associated with ER. Recently, Shimizu T et al. reported that high levels of 
S-pancreas-1 antigen and CA19-9 were independent risk factors for ER in PDAC patients undergoing surgical resection (43). In line with previous observations, our results showed that high preoperative CA19-9 levels were an independent predictor for ER.

Histological characteristics have also been extensively studied in relation to patient outcomes. Poor differentiation of PDAC tumors has been identified to have a negative effect on survival after resection (3, 44-48). Histological characteristics of tumors may additionally enhance the predictive value of AJCC staging in resectable PDAC (47). A post-resection nomogram including tumor differentiation has also been developed (49) and validated (50) to predict the survival of PDAC patients undergoing resection. In this study, tumor differentiation was found to significantly affect ER in PDAC patients after radical resection. Interestingly, although the TNM staging system has been well known as a reliable predictor of long-term outcomes, our results did not show a significant correlation of TNM stage with ER.

In conclusion, high CA19-9 levels, CD44 H-scores and poor differentiation were independent predictors for ER in PDAC patients undergoing radical resection. Therefore, the determination of CD44 expression may help in identifying patients at a high risk of ER for more aggressive treatment after radical surgery.

\section{Conflicts of Interest}

All Authors declare that no conflicts of interest exist regarding this study.

\section{Acknowledgements}

The Authors thank Shu-Fang Huang for maintaining the pancreatic cancer database and assisting in statistical analysis. This work was partly supported by the Chang Gung Medical Research Program, Taiwan (CORPG3E0153).

\section{References}

1 Siegel RL, Miller KD and Jemal A: Cancer statistics, 2017. CA Cancer J Clin 67(1): 7-30, 2017.

2 Salvia R, Fernandez-del Castillo C, Bassi C, Thayer SP, Falconi M, Mantovani W, Pederzoli P and Warshaw AL: Main-duct intraductal papillary mucinous neoplasms of the pancreas: Clinical predictors of malignancy and long-term survival following resection. Ann Surg 239(5): 678-685, 2004.

3 Sohn TA, Yeo CJ, Cameron JL, Koniaris L, Kaushal S, Abrams RA, Sauter PK, Coleman J, Hruban RH and Lillemoe KD: Resected adenocarcinoma of the pancreas-616 patients: Results, outcomes, and prognostic indicators. J Gastrointest Surg 4(6): 567-579, 2000.

4 Hsu CP, Hsu JT, Liao CH, Kang SC, Lin BC, Hsu YP, Yeh CN, Yeh TS and Hwang TL: Three-year and five-year outcomes of surgical resection for pancreatic ductal adenocarcinoma: Longterm experiences in one medical center. Asian J Surg 41(2): 115123, 2018.

5 Abel EV and Simeone DM: Biology and clinical applications of pancreatic cancer stem cells. Gastroenterology 144(6): 12411248, 2013.

6 Visvader JE and Lindeman GJ: Cancer stem cells in solid tumours: Accumulating evidence and unresolved questions. Nat Rev Cancer 8(10): 755-768, 2008.

7 Aruffo A, Stamenkovic I, Melnick M, Underhill CB and Seed $\mathrm{B}$ : $\mathrm{Cd} 44$ is the principal cell surface receptor for hyaluronate. Cell 61(7): 1303-1313, 1990.

8 Marhaba R and Zoller M: Cd44 in cancer progression: Adhesion, migration and growth regulation. J Mol Histol 35(3): 211-231, 2004.

9 Zoller M: Cd44: Can a cancer-initiating cell profit from an abundantly expressed molecule? Nat Rev Cancer 11(4): 254-267, 2011.

$10 \mathrm{Hu}$ Y and Fu L: Targeting cancer stem cells: A new therapy to cure cancer patients. Am J Cancer Res 2(3): 340-356, 2012.

11 Wood NJ: Pancreatic cancer: Pancreatic tumour formation and recurrence after radiotherapy are blocked by targeting cd44. Nat Rev Gastroenterol Hepatol 11(2): 73, 2014.

12 Jiang W, Zhang Y, Kane KT, Collins MA, Simeone DM, di Magliano MP and Nguyen KT: Cd44 regulates pancreatic cancer invasion through mt1-mmp. Mol Cancer Res 13(1): 9-15, 2015.

13 Chen J, Zhou J, Lu J, Xiong H, Shi X and Gong L: Significance of cd44 expression in head and neck cancer: A systemic review and meta-analysis. BMC Cancer 14: 15, 2014.

14 Luo Z, Wu RR, Lv L, Li P, Zhang LY, Hao QL and Li W: Prognostic value of cd44 expression in non-small cell lung cancer: A systematic review. Int J Clin Exp Pathol 7(7): 36323646, 2014.

15 Fang M, Wu J, Lai X, Ai H, Tao Y, Zhu B and Huang L: Cd44 and cd44v6 are correlated with gastric cancer progression and poor patient prognosis: Evidence from 42 studies. Cell Physiol Biochem 40(3-4): 567-578, 2016.

16 Luo Y and Tan Y: Prognostic value of cd44 expression in patients with hepatocellular carcinoma: Meta-analysis. Cancer Cell Int 16: 47, 2016.

17 Li X, Ma X, Chen L, Gu L, Zhang Y, Zhang F, Ouyang Y, Gao $Y$, Huang $Q$ and Zhang X: Prognostic value of cd44 expression in renal cell carcinoma: A systematic review and meta-analysis. Sci Rep 5: 13157, 2015.

18 Lin J and Ding D: The prognostic role of the cancer stem cell marker cd44 in ovarian cancer: A meta-analysis. Cancer Cell Int 17: 8, 2017.

19 Trochon V, Mabilat C, Bertrand P, Legrand Y, Smadja-Joffe F, Soria C, Delpech B and Lu H: Evidence of involvement of cd44 in endothelial cell proliferation, migration and angiogenesis in vitro. Int J Cancer 66(5): 664-668, 1996.

20 Savani RC, Cao G, Pooler PM, Zaman A, Zhou Z and DeLisser HM: Differential involvement of the hyaluronan (ha) receptors cd44 and receptor for ha-mediated motility in endothelial cell function and angiogenesis. J Biol Chem 276(39): 36770-36778, 2001.

21 Cao G, Savani RC, Fehrenbach M, Lyons C, Zhang L, Coukos $\mathrm{G}$ and Delisser HM: Involvement of endothelial cd44 during in vivo angiogenesis. Am J Pathol 169(1): 325-336, 2006.

22 Choi GH, Kim GI, Yoo JE, Na DC, Han DH, Roh YH, Park YN and Choi JS: Increased expression of circulating cancer stem cell 
markers during the perioperative period predicts early recurrence after curative resection of hepatocellular carcinoma. Ann Surg Oncol 22: S1444-1452, 2015.

23 Hwang T-L, Lee L-Y, Chen T-C, Thorat A, Hsu J-T, Yeh C-N, Yeh T-S and Jan Y-Y: Prognosis of ductal adenocarcinoma of pancreatic head with overexpression of cd44. Formosan Journal of Surgery 47(4): 138-144, 2014.

24 Gotoda T, Matsumura Y, Kondo H, Saitoh D, Shimada Y, Kosuge T, Kanai Y and Kakizoe T: Expression of cd44 variants and its association with survival in pancreatic cancer. Jpn J Cancer Res 89(10): 1033-1040, 1998.

25 Li L, Hao X, Qin J, Tang W, He F, Smith A, Zhang M, Simeone DM, Qiao XT, Chen ZN, Lawrence TS and Xu L: Antibody against cd44s inhibits pancreatic tumor initiation and postradiation recurrence in mice. Gastroenterology 146(4): 11081118, 2014.

26 Koopmann J, Rosenzweig CN, Zhang Z, Canto MI, Brown DA, Hunter M, Yeo C, Chan DW, Breit SN and Goggins M: Serum markers in patients with resectable pancreatic adenocarcinoma: Macrophage inhibitory cytokine 1 versus ca19-9. Clin Cancer Res 12(2): 442-446, 2006.

27 Kaur S, Smith LM, Patel A, Menning M, Watley DC, Malik SS, Krishn SR, Mallya K, Aithal A, Sasson AR, Johansson SL, Jain M, Singh S, Guha S, Are C, Raimondo M, Hollingsworth MA, Brand RE and Batra SK: A combination of muc5ac and ca19-9 improves the diagnosis of pancreatic cancer: A multicenter study. Am J Gastroenterol 112(1): 172-183, 2017.

28 Capello M, Bantis LE, Scelo G, Zhao Y, Li P, Dhillon DS, Patel NJ, Kundnani DL, Wang H, Abbruzzese JL, Maitra A, Tempero MA, Brand R, Firpo MA, Mulvihill SJ, Katz MH, Brennan P, Feng Z, Taguchi A and Hanash SM: Sequential validation of blood-based protein biomarker candidates for early-stage pancreatic cancer. J Natl Cancer Inst 109(4), 2017.

29 Balasenthil S, Huang Y, Liu S, Marsh T, Chen J, Stass SA, KuKuruga D, Brand R, Chen N, Frazier ML, Jack Lee J, Srivastava S, Sen S and McNeill Killary A: A plasma biomarker panel to identify surgically resectable early-stage pancreatic cancer. J Natl Cancer Inst 109(8), 2017.

30 Maisey NR, Norman AR, Hill A, Massey A, Oates J and Cunningham D: Ca19-9 as a prognostic factor in inoperable pancreatic cancer: The implication for clinical trials. $\mathrm{Br} \mathrm{J}$ Cancer 93(7): 740-743, 2005.

31 Berger AC, Garcia M, Jr., Hoffman JP, Regine WF, Abrams RA, Safran H, Konski A, Benson AB, 3rd, MacDonald J and Willett CG: Postresection ca 19-9 predicts overall survival in patients with pancreatic cancer treated with adjuvant chemoradiation: A prospective validation by rtog 9704. J Clin Oncol 26(36): 59185922, 2008.

32 Koom WS, Seong J, Kim YB, Pyun HO and Song SY: Ca 19-9 as a predictor for response and survival in advanced pancreatic cancer patients treated with chemoradiotherapy. Int J Radiat Oncol Biol Phys 73(4): 1148-1154, 2009.

33 Kondo N, Murakami Y, Uemura K, Hayashidani Y, Sudo T, Hashimoto Y, Nakashima A, Sakabe R, Shigemoto N, Kato Y, Ohge $\mathrm{H}$ and Sueda T: Prognostic impact of perioperative serum ca 19-9 levels in patients with resectable pancreatic cancer. Ann Surg Oncol 17(9): 2321-2329, 2010.

34 Abdel-Misih SR, Hatzaras I, Schmidt C, Saab TB, Klemanski D, Muscarella P, Melvin WS, Ellison EC and Bloomston M: Failure of normalization of ca19-9 following resection for pancreatic cancer is tantamount to metastatic disease. Ann Surg Oncol 18(4): 1116-1121, 2011.

35 Humphris JL, Chang DK, Johns AL, Scarlett CJ, Pajic M, Jones MD, Colvin EK, Nagrial A, Chin VT, Chantrill LA, Samra JS, Gill AJ, Kench JG, Merrett ND, Das A, Musgrove EA, Sutherland RL, Biankin AV and Network NSWPC: The prognostic and predictive value of serum ca19.9 in pancreatic cancer. Ann Oncol 23(7): 1713-1722, 2012.

36 Maithel SK, Maloney S, Winston C, Gonen M, D'Angelica MI, Dematteo RP, Jarnagin WR, Brennan MF and Allen PJ: Preoperative ca 19-9 and the yield of staging laparoscopy in patients with radiographically resectable pancreatic adenocarcinoma. Ann Surg Oncol 15(12): 3512-3520, 2008.

37 Karachristos A, Scarmeas N and Hoffman JP: Ca 19-9 levels predict results of staging laparoscopy in pancreatic cancer. J Gastrointest Surg 9(9): 1286-1292, 2005.

38 Fujioka S, Misawa T, Okamoto T, Gocho T, Futagawa Y, Ishida $\mathrm{Y}$ and Yanaga $\mathrm{K}$ : Preoperative serum carcinoembryonic antigen and carbohydrate antigen 19-9 levels for the evaluation of curability and resectability in patients with pancreatic adenocarcinoma. J Hepatobiliary Pancreat Surg 14(6): 539-544, 2007.

39 Kilic M, Gocmen E, Tez M, Ertan T, Keskek M and Koc M: Value of preoperative serum ca 19-9 levels in predicting resectability for pancreatic cancer. Can J Surg 49(4): 241-244, 2006.

40 Bergquist JR, Puig CA, Shubert CR, Groeschl RT, Habermann EB, Kendrick ML, Nagorney DM, Smoot RL, Farnell MB and Truty MJ: Carbohydrate antigen 19-9 elevation in anatomically resectable, early stage pancreatic cancer is independently associated with decreased overall survival and an indication for neoadjuvant therapy: A national cancer database study. J Am Coll Surg 223(1): 52-65, 2016.

41 Ferrone CR, Finkelstein DM, Thayer SP, Muzikansky A, Fernandez-delCastillo C and Warshaw AL: Perioperative ca199 levels can predict stage and survival in patients with resectable pancreatic adenocarcinoma. J Clin Oncol 24(18): 2897-2902, 2006.

42 Hallemeier CL, Botros M, Corsini MM, Haddock MG, Gunderson LL and Miller RC: Preoperative ca 19-9 level is an important prognostic factor in patients with pancreatic adenocarcinoma treated with surgical resection and adjuvant concurrent chemoradiotherapy. Am J Clin Oncol 34(6): 567-572, 2011.

43 Shimizu T, Asakuma M, Tomioka A, Inoue Y, Hirokawa F, Hayashi M and Uchiyama K: Span-1 and ca19-9 as predictors of early recurrence and lymph node metastasis for patients with invasive pancreatic cancer after pancreatectomy. Am Surg 84(1): 109-113, 2018.

44 Geer RJ and Brennan MF: Prognostic indicators for survival after resection of pancreatic adenocarcinoma. Am J Surg 165(1): 68-72, 1993.

45 Millikan KW, Deziel DJ, Silverstein JC, Kanjo TM, Christein JD, Doolas A and Prinz RA: Prognostic factors associated with resectable adenocarcinoma of the head of the pancreas. Am Surg 65(7): 618-623, 1999.

46 Benassai G, Mastrorilli M, Quarto G, Cappiello A, Giani U and Mosella G: Survival after pancreaticoduodenectomy for ductal adenocarcinoma of the head of the pancreas. Chir Ital 52(3): 263-270, 2000 
47 Helm J, Centeno BA, Coppola D, Melis M, Lloyd M, Park JY, Chen DT and Malafa MP: Histologic characteristics enhance predictive value of american joint committee on cancer staging in resectable pancreas cancer. Cancer 115(18): 4080-4089, 2009.

48 Crippa S, Partelli S, Zamboni G, Barugola G, Capelli P, Inama M, Bassi C, Pederzoli P and Falconi M: Poorly differentiated resectable pancreatic cancer: Is upfront resection worthwhile? Surgery 152: S112-119, 2012.

49 Brennan MF, Kattan MW, Klimstra D and Conlon K: Prognostic nomogram for patients undergoing resection for adenocarcinoma of the pancreas. Ann Surg 240(2): 293-298, 2004.
50 Ferrone CR, Kattan MW, Tomlinson JS, Thayer SP, Brennan MF and Warshaw AL: Validation of a postresection pancreatic adenocarcinoma nomogram for disease-specific survival. J Clin Oncol 23(30): 7529-7535, 2005.
Received July 26, 2018

Revised August 9, 2018

Accepted August 10, 2018 